\title{
Viral Hepatitis B Seroprevalence Among Pregnant Women in Tlemcen
}

\section{H Brahimi ${ }^{1,3 *}$ and DJ Bacha ${ }^{2}$}

${ }^{1}$ Infectious Disease Department, University Hospital Center, Tlemcen, Algeria

${ }^{2}$ Infectious Disease Department, Ain Naadja Military Hospital, Algiers, Algeria

${ }^{3}$ Faculty of Medicine, University of Abu Bakr Belkaid, Tlemcen, Algeria

*Corresponding Author: H Brahimi, Infectious Disease Department, University

Hospital Center, Tlemcen, Algeria.
Received: November 08, 2021

Published: December 13, 2021

(C) All rights are reserved by $\mathbf{H}$ Brahimi and

DJ Bacha.

\begin{abstract}
The epidemiology of viral hepatitis B in pregnancy is not precisely known in Algeria, although it is of primary importance to health planners and program managers. The objective of this study was to assess the prevalence of these infections in the population of pregnant women. This is a prospective longitudinal study carried out at the level of the mother-child specialized hospital and mother-child protection centers in the region of Tlemcen. This study lasted 30 months (January 2013 to June 2015), and recruited 2165 pregnant women. The seroprevalence of HBs Ag in pregnant women was 1.8\%. The mean maternal age of HBs Ag positive patients was $30.38 \pm 5.9$ years, with the most affected age group of $30-39$ years with $51.28 \%$. There was no statistically significant association between age or socio-demographic factors (level of education, marital status, surgical procedures, previous hospitalization, previous transfusions, dental care, history of sexually transmitted infections or scarifications, gestational age) and HBs Ag status. On the other hand, other socio demographic factors such as parity $(\mathrm{P}=0.014)$, professional activity $(\mathrm{P}=0.031)$, history of jaundice $(\mathrm{P}=0.014)$, mode of delivery $(\mathrm{P}=0.012)$, piercing $(\mathrm{P}=0.034)$, intravenous drug addiction $(\mathrm{P}=0.005)$, vagrancy $(\mathrm{P}=0.02)$, and family history of hepatitis B $(\mathrm{P}<0.001)$ were associated with HBsAg carriage. Chronic mutant carriers $(87.2 \%)$ vs. 12.8\% chronic wild-type. These results encourage the screening of viral hepatitis $B$ in pregnant women in order to prevent vertical transmission of this virus. These results encourage screening for viral hepatitis B in pregnant women in order to prevent vertical transmission of this virus.
\end{abstract}

Keywords: Viral Hepatitis B; Pregnancy; Prevalence; Risk Factors

\section{Introduction}

Both by their frequency and by their potential severity, viral hepatitis «B» constitutes a major public health problem. Globally, approximately 370 to 400 million people are estimated to be chronic carriers of the hepatitis B virus [1]. Algeria, a country considered to be «emerging», in the midst of an epidemiological transition, is in an area of moderate endemicity for hepatitis B with a prevalence rate of $2-7 \%$ according to the WHO [2]. Mother-to-child transmission of hepatitis B virus is the main cause of chronic HBs Ag carrier [3]. In highly endemic countries, the prevalence of HBs $\mathrm{Ag}$ in pregnant women is $35-50 \%$, and perinatal transmission of
HBV is $30 \%$. In Algeria [4], according to a national epidemiological seroprevalence survey in 1998, the prevalence of HBV in pregnant women is $1.8 \%$, it still remains low in pregnant women compared to the general population. The national prevalence of $2.15 \%$ in 1998 , is heterogeneous according to the regions considered : in Algiers [5], the prevalence is $1.06 \%$ in 2007-2008. In Annaba [6], this prevalence was $2.47 \%$ in the period 2003-2004. The risk of maternal-fetal transmission of HBs Ag was $80-90 \%$ if the mother is HBe $(+)$ and DNA (+), 30\% if DNA is undetectable [7]. However, it should be noted that there are no studies on the impact of viral hepatitis $\mathrm{B}$ in pregnant women in western Algeria, particularly in Tlemcen. 


\section{Materials and Methods}

We conducted a prospective longitudinal study carried out at the level of the mother-child specialized hospital and mother-child protection centers in the region of Tlemcen. The study lasted 30 months (January 2013 to June 2015), and recruited 2165 pregnant women.

The detection of HBs Ag was carried out during the 1st prenatal consultation of pregnant women, using rapid diagnostic tests (Hexagon HBs Ag, Human laboratory), while the confirmation was serological, using the 3rd generation ELISA kit. Other hepatitis B markers were also tested, thus quantification of the viral load of HBV DNA, using TaqMan Roche real-time PCR «RT-PCR». We used statistical software (SPSS) version 21.0 and performed a quantitative analysis of the derived data, looking for the association of categorical variables $(\mathrm{P}<0.05)$.

\section{Results}

In the present study, the seroprevalence of HBs Ag in pregnant women attending antenatal clinics was $1.8 \%$. The mean maternal age of HBs Ag positive patients was $30.38 \pm 5.9$ years, with the most affected age group of 30-39 years with $51.28 \%$ (Figure 1). The patients with university level education were predominant (30\%) and only $10 \%$ were uneducated. The majority of pregnant women $(97.4 \%)$ were married and only $2.6 \%$ of cases were single. Multiparous women were found with a frequency of $23 \%$ (Figure 2). About $70 \%$ of pregnant women were housewives (Figure 3 ). The mean value of BMI (body mass index) of our patients, was $28.86 \pm 5.28 \mathrm{~kg}$ / $\mathrm{m}^{2}\left[16.30-40.62 \mathrm{~kg} / \mathrm{m}^{2}\right]$. The majority of pregnant women $(79.5 \%)$ tested positive for HBs Ag before the term of pregnancy (Figure 4). Almost $50 \%$ of the patients had cases of hepatitis B in the family. There was no statistically significant association between age or other socio-demographic factors (level of education, marital status, surgical procedures, previous hospitalization, previous transfusions, dental treatment, history of sexually transmitted infections or scarifications, gestational age) and HBs Ag status. On the other hand, in univariate analysis other factors were linked to the carriage of HBs Ag such as parity $(P=0.014)$, professional activity $(\mathrm{P}=0.031)$, history of jaundice $(\mathrm{P}=0.014)$, mode of delivery $(\mathrm{P}=$ 0.012), piercing $(P=0.034)$, intravenous drug abuse $(P=0.005)$, vagrancy $(\mathrm{P}=0.02)$ and family history of hepatitis $\mathrm{B}(\mathrm{P}<0.001)$.

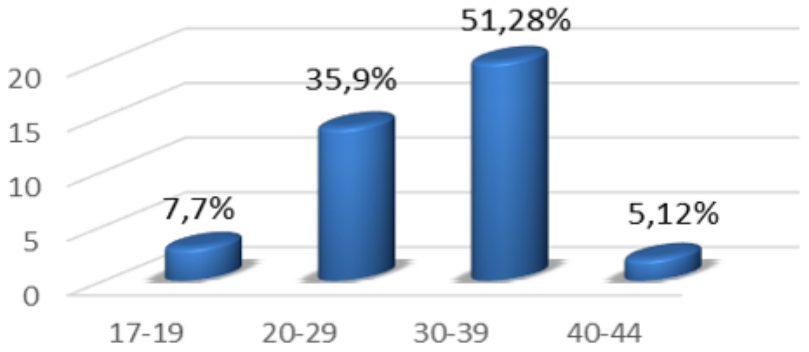

Figure 1: Distribution of pregnant women HBs Ag positive by age.

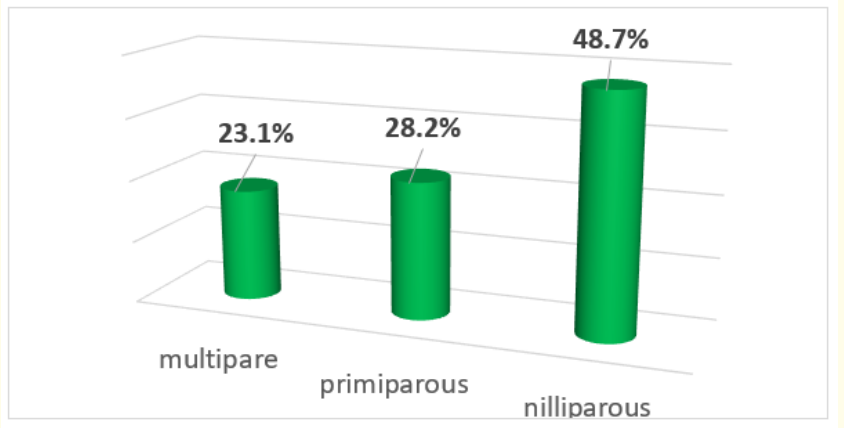

Figure 2: Distribution of pregnant women HBs Ag positive according to parity.

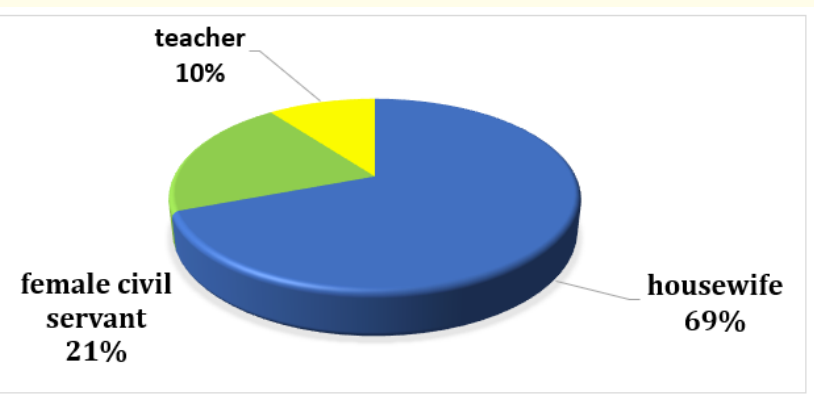

Figure 3: Distribution of pregnant women HBs Ag positive according to professional activity. 


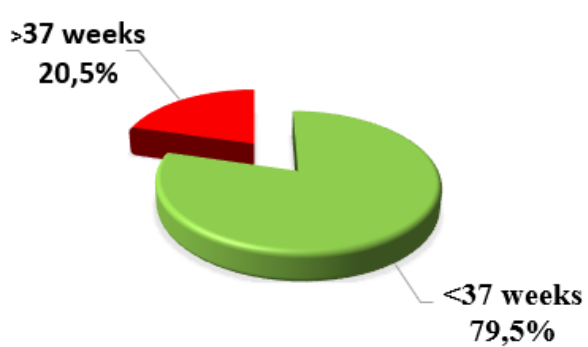

Figure 4: Distribution of pregnant women $\mathrm{HBs} \mathrm{Ag}$ positive according to gestational age.

We noticed that chronic B carriers with mutant virus with a frequency of $87.2 \%$ vs. $12.8 \%$ of chronic wild virus B carriers. The mean viral load was $2.76 \pm 1.71 \log 10 \mathrm{IU} / \mathrm{ml}$ with extremes ranging from undetectable HBV DNA to $8.23 \log ^{10} \mathrm{IU} / \mathrm{ml}$. Most patients $(84.6 \%)$ with mutant virus had a low viral load $(<2000 \mathrm{IU} / \mathrm{ml})$, while $13 \%$ of patients had high viraemia (> 20,000 IU/ml). However, a patient with wild virus B had HBV DNA low.

\section{Discussion}

In our study, the seroprevalence of HBs Ag in pregnant women was $1.8 \%$. It is consistent with that observed in the general population [4]. Globally, this result confirms Algeria's place as an intermediate zone of medium endemicity for HBV, between Europe and America with low prevalence and Sub-Saharan Africa with higher prevalence. This value is close to that of the general population found in the national sero epidemiological survey in 1998 [4], also close to that reported by Bensalem., et al. [5] with a prevalence of $1.06 \%$, for 3578 patients screened between 2007 and 2008, in the laboratory of the Pasteur Institute in Algiers, and those reported in other studies carried out in the East and in the Center of the country [6]. In an older study of the prevalence of serum markers, conducted by Ayed., et al. [8], on a sample of 715 pregnant women, from July 1992 to February 1993, the prevalence rate was 1.6\%. These similar results could be explained by the existence of national epidemiological homogeneity.

The data in the literature are very heterogeneous on the subject. Thus, if our prevalence is close to that found in Libya [9], with a rate of $1.5 \%$, it nevertheless differs from the high rates reported in other Maghreb countries. In the survey by Sbiti., et al. [10] concer- ning 1120 Moroccan pregnant women, from January 2014 to December 2015, the seroprevalence of HBs Ag was 2.35\%. The study carried out in the Tunisian center, in 2006 by Hannachi., et al. [11] showed a prevalence of HBs Ag in pregnant women of 3\%. In Mauritania, Mansour., et al. [12] found a seroprevalence of $10.7 \%$, in a population of 1020 screened pregnant women, from December 2008 to March 2009. The heterogeneity of the results can be attributed to particularities in the modes of transmission of HBV, linked to socio-cultural practices and different environmental factors in the Maghreb countries.

In addition, the epidemiological situation is totally different in the Middle East with much higher prevalence. In Egypt, Zahran., et al. [13] found a seroprevalence of 5.6\% in Egyptian pregnant women screened, in 2010 and in Yemen, according to Al-Shamahy., et al. [14], the prevalence was $13.2 \%$ in 2000 . This difference in prevalence may be linked to the high frequency of particular customs in these regions (circumcision of young girls, tattooing, piercing).

Our prevalence is also lower than those reported in sub-Saharan African countries, although most studies date back more than ten years : $6.5 \%$ in Congo [15], 9.5\% in Gabon [16], 10.7\% in Burkina Faso [17], and $16.6 \%$ in Niger [18].

A recent HBs Ag prevalence study carried out from December 2013 to March 2014 in a rural area in Cameroon [19], involving a sample of 325 pregnant women, found a prevalence of $10.2 \%$. Another study conducted in Ghana, by Candotti., et al. [20] showed a seroprevalence of $12.6 \%$ in his series. In Senegal, Touré-Fall., et al. [21] identified $13.8 \%$ of HBs Ag in pregnant women screened in 2008. However, the highest prevalence of around $25 \%$ was reported, by Madzime., et al. [22] in Zimbabwe.

These high figures among pregnant women, in these highly endemic regions, may be related to the persistence of risky behavior in this population. Although some women come from polygamous households, without knowledge of the status of the spouse, and vaccination against this virus is almost absent.

However, our result was higher than those found in other countries around the Mediterranean, such as Italy [23] with a prevalence of $0.86 \%$, France [24] with $0.65 \%$, and Spain [25] with $0.75 \%$. In a prevalence study carried out in Greece [26], which included 13,581 pregnant women, the prevalence of HBs Ag was 1.15\%. The study conducted in North Central London by Godbole., et al. [27], on a 
sample of 38,227 pregnant women studied during antenatal care between 2009 and 2010, found 401 "HBs Ag positive" cases, that is a prevalence of $1.05 \%$.

In Western countries, this low prevalence is linked, in particular, to the low endemicity of hepatitis B, the high socio-cultural level and the mandatory screening for hepatitis B during antenatal consultations. Although there were no foreign pregnant women in our series, immigration nevertheless plays an important role in the variations in the prevalence rates of HBV infection in Western countries with the reception of pregnant women from regions highly endemic, such as Asia or Africa, express much higher prevalence rates. This is well illustrated in a Danish study [28] which shows that the prevalence of HBs Ag in pregnant women, regardless of their ethnic origins, was $0.26 \%$, while it was $14 \%$ for women from Southeast Asia.

In France [29], a multicenter study was carried out shortly after the introduction of compulsory screening in 1992, in 12 university centers, for 21476 women (16 351 women of French origin and 5125 of foreign origin). In this study, the average prevalence of HBs Ag was $0.72 \%$ but very variable depending on the center $(0.13 \%$ in Limoges vs. $2.99 \%$ in Montpellier). In addition, this study confirmed the difference in the prevalence of Ag HBs between French women $(0.15 \%)$ and immigrant women $(2.56 \%)$.

This difference in prevalence is associated not only with the country of birth, with intravenous drug use, but also with other factors such as socio-economic level, level of education and stay of at least 3 months in an institution.

These results further confirm the value of compulsory screening during pregnancy, and plead in favor of the promotion of screening outside pregnancy, in particular among people in precarious situations.

In our study population, the mean maternal age is $30.38 \pm 5.9$ years (17-44 years) with the most affected age group was between 30-39 years (51.28\%) (Figure 1). Our results concerning age were compared with those of the Maghreb countries belonging to the same endemic zone. Tunisian patients [7] were younger, with an average age of 29 years, and 28 years with extremes of 17 and 43 years for Moroccan patients [30].

Similar results were also found in other studies carried out in
Asian countries such as China [31] where the average age was 30.7 \pm 3.6 years, and it was $27.4 \pm 5,8$ years in Indonesia [32]. In these countries, the socio-cultural level was high, and the gestational age was later. In our country, the major mode of contamination by the HBV virus in the general population is probably dental care, which is found with a frequency of $82.5 \%$ in our study population and $85 \%$ in $\mathrm{HBs}$ Ag positive mothers, but no significant difference was found between HBV infection and dental care $(\mathrm{P}=0.83)$. Our results are in agreement with those reported in several studies in the literature $[34,38,39]$. There was also no statistically significant association between age or other socio-demographic factors (level of education, marital status, surgical procedures, previous hospitalization, previous transfusions, history of sexually transmitted infections or scarifications, gestational age) and HBs Ag status. On the other hand, in univariate analysis other factors were linked to the carriage of HBs Ag such as parity $(\mathrm{P}=0.014)$, professional activity $(\mathrm{P}=0.031)$, history of jaundice $(\mathrm{P}=0.014)$, delivery mode $(\mathrm{P}=$ 0.012), piercing $(\mathrm{P}=0.034)$, intravenous drug addiction $(\mathrm{P}=0.005)$ and vagrancy $(\mathrm{P}=0.02)$, thus joining us several works in the literature [33-36]. The family history of hepatitis B was also a major risk factor $(\mathrm{P}<0.001)$, this had joined several studies in the literature $[7,19,37]$. Family exposure to the HBV virus is frequent, and calls out to us the reality of horizontal intra-family transmission.

In fact, the existence of a positive HBsAg family member is a potential risk factor for intra-family transmission of HBV. Intra-family transmission of hepatitis B has been the subject of numerous scientific studies which have reported the possibility of transmission of HBV between people who share the same household.

In addition, multivariate analysis by logistic regression showed that only therapeutic piercing $(\mathrm{P}=0.019)$ is associated with carriage of $\mathrm{HBs} \mathrm{Ag}$ in pregnant women. In the literature, tattooing and piercing are described as important risk factors (46\%) for the transmission of hepatitis B in a study carried out in 2000 by Michault., et al. [40] for 100 inmates. In the study by Eke., et al. [34], scarification and tattooing appear to be the only factors associated with HBV infection in mothers $(\mathrm{P}=0.001)$.

We noticed that chronic B carriers with mutant virus with a frequency of $87.2 \%$ vs. $12.8 \%$ of chronic wild virus B carriers. The «mutant» profile was predominant, comparable to the $11.1 \%$ reported by Ilboudo., et al. [41] in Ouagadougou. However, this rate is lower than the $20.9 \%$ found by Sbiti., et al. [10], in Morocco, $21.7 \%$ 
\% reported by El-Magrehe., et al. [9] in Libya, and the $18.2 \%$ reported by Nacro., et al. [17] in Bobo-Dioulasso in Burkina Faso. On the other hand, higher rates are reported in Burkina Faso by Sangaré., et al. [42] at 31.4\% ; Al-Shamahy [14] reported a high rate of $60 \%$ in HBe Ag positive mothers in Sana'a, Yemen.

\section{Conclusion}

Our study has provided knowledge on the extent of viral hepatitis B in pregnant women in the region of Tlemcen, which involves the implementation of measures to prevent mother-to-child transmission. The success of early screening in the population of pregnant women relies primarily on rigorous planning and a well-organized and sustainable program that aims to reduce the risk of viral transmission, as well as the continuity and quality of interventions throughout the duration of treatment Care.

\section{Bibliography}

1. Ott JJ., et al. "The risk of perinatal hepatitis B virus transmission : hepatitis B e antigen (HBeAg) prevalence estimates for all world regions". BMC Infect Dis 12 (2012): 131.

2. Aspinall EJ., et al. "Hepatitis B prevention, diagnosis, treatment and care: A review". Occupational medicine 61.8 (2011): 53140.

3. Khan Salman., et al. "Hepatitis B virus infection in pregnant women and transmission to newborns". Asian Pac J Too Say 5.6 (2015): 421-429

4. Tebbal. S., et al. "National sero-epidemiological survey of Ag HBS in Algeria”. (1998).

5. Bensalem A. "Prevalence of HBs Ag and detection of HBV-DNA in pregnant women in the Algiers region" (2010).

6. Aidaoui M., et al. "Seroprevalence of HIV infection among pregnant women in the region of Annaba (Algeria)". Journal of epidemiology and public health 56: 261-266.

7. Ranger-Rogez S., et al. "Hepatitis viruses : mother-to-child transmission". Pathology Biology 50 (2002): 568-575.

8. Ayed Z., et al. "Prevalence of serum markers of hepatitis B and $\mathrm{C}$ in blood donors and pregnant women in Algeria". Bull Soc Pathol Exot 88.5 (1995): 225-8.

9. El-Magrahe H., et al. "Maternal and neonatal seroprevalence of Hepatitis B surface antigen (HBsAg) in Tripoli, Libya”. Journal of Infection in Developing Countries 4.3 (2010): 168-170.
10. Sbiti M. "HBsAg seroprevalence in pregnant women in central Morocco". The Pan African Medical Journal 24 (2016): 187.

11. Hannachi N., et al. "Viral hepatitis B in Tunisian pregnant women : risk factors and interest in the study of viral replication in the case of negative HBe antigen". Pathology Biology 57.3 (2009): 43-47.

12. Mansour W., et al. "Virological and epidemiological features of hepatitis delta infection among blood donors in Nouakchott, Mauritania". Journal of Clinical Virology 55 (2012): 12-6.

13. Zahran KM., et al. "Pattern of hepatitis virus infection among pregnant women and their newborns at the Women's Health Center of Assiut University, Upper Egypt". International Journal of Gynecology \& Obstetrics 111 (2010): 171-174.

14. Al-Shamahy H. "Prevalence of hepatitis B surface antigen and risk factors of HBV infection in a sample of healthy mothers and their infants in Sana'a, Yemen". Annals of Saudi Medicine 20 (2000): 464-467.

15. Itoua-Ngaporo A., et al. "Prevalence of hepatitis B viral markers in a population of pregnant women in Brazzaville (Congo)". European Journal of Obstetrics \& Gynecology and Reproductive Biology 24.5 (1995): 534-536.

16. Makuwa M., et al. "Prevalence and genetic diversity of hepatitis B and delta viruses in pregnant women in Gabon : molecular evidence that hepatitis delta virus clade 8 originates from and is endemic in central Africa". Journal of Clinical Microbiology 46 (2008): 754-756.

17. Nacro B., et al. "HBs antigen carrier state in pregnant women in Bobo Dioulasso (Burkina Faso)”. Dakar Medical 45.2 (2000): 188-190.

18. Mamadou S., et al. "HIV infection and hepatitis B seroprevalence among antenatal clinic attendees in Niger, West Africa". HIV AIDS (Auckl) 4 (2012): 1-4.

19. Fomulu NJ., et al. "Prevalence, correlates and pattern of Hepatitis B among antenatal clinic attenders in Yaounde-Cameroon : is perinatal transmission of HBV neglected in Cameroon?" BMC Pregnancy and Childbirth 13(2013): 158.

20. Candotti D., et al. "Maternofetal transmission of hepatitis B virus genotype E in Ghana, west Africa". Journal of General Virology 88 (2007): 2686-2695.

21. Touré-Fall AO., et al. "Residual risk of transmission of HIV and HBV, in Senegalese national blood bank from 2003 to 2005". Transfusion Clinique et Biologique 16 (2009): 439-443. 
22. Madzime S., et al. "Hepatitis B virus infection among pregnant women delivering at Harare Maternity Hospital, Harare Zimbabwe, 1996 to 1997". Central African Journal of Medicine 45.8 (1999): 195-198.

23. Nardiello S., et al. "Infezione da HBV in gravidanza HBV and pregnancy". The Infezioni in Medicina 3 (2011): 139-146.

24. Denis F., et al. "Screening of pregnant women for hepatitis B markers in a French Provincial University Hospital (Limoges) during 15 years". European Journal of Epidemiology 19 (2004): 973-978.

25. Bonura F, et al . "Pregnant women as a sentinel population to target and implement hepatitis B virus (HBV) vaccine coverage: a three-year survey in Palermo, Sicily". Vaccine 23 (2005): 3243-3246.

26. Panagopoulos P., et al. "Prevalence of hepatitis B and C in the maternity department in a Greek district hospital". Journal of Maternal-Fetal and Neonatal Medicine 16 (2004): 106-110.

27. Godbole G., et al. "Management of hepatitis B in pregnant women and infants: a multicentre audit from four London hospitals". BMC Pregnancy and Childbirth 13 (2013): 222.

28. Harder KM., et al. "Universal screening for hepatitis B among pregnant women led to $96 \%$ vaccination coverage among newborns of HBs Ag positive mothers in Denmark". Vaccine 29.50 (2011): 9303-9307.

29. Bacq Y. "Viral hepatitis B and Pregnancy". Clinical and biological gastroenterology 32 (2008): S12 - S19.

30. Sekkat M. "Prevalence of HBsAg in pregnant women : preliminary results of a study prospective conducted at Hassan II University Hospital Fez Morocco About 156 cases". Specialist diploma thesis (2010).

31. Tan H-H., et al. "Chronic hepatitis B virus (HBV) infection in pregnancy”. Hepatology International 2 (2008): 370-375.

32. Gunardi H., et al. "Current Prevalence of Hepatitis B Infection among Parturient Women in Jakarta, Indonesia”. The Indonesian Journal of Internal Medicine 46.1 (2014).

33. Dwivedi M., et al. "Seroprevalence of hepatitis B infection during pregnancy and risk of perinatal transmission". Indian J Gastroenterol 30.2: 66-71.

34. Eke AC., et al. "Prevalence, correlates and pattern of hepatitis B surface antigen in a low resource setting". Virology Journal 8 (2011): 12
35. Sbai A., et al. HBV genotypes in Morocco. Journal of clinical virology 38 (2007): 184-185.

36. Romanò L., et al. "The changing face of the epidemiology of type A, B, and D viral hepatitis in Italy, following the implementation of vaccination". Vaccine 27 (2009): 3439-3442.

37. El-Karaksy HM., et al. "Applicability and efficacy of a model for prevention of perinatal transmission of hepatitis B virus infection: Single center study in Egypt". World J Gastroenterol 20.45 (2014): 17075-17083.

38. Noubiap JJ., et al. "Prevalence, infectivity and correlates of hepatitis B virus infection among pregnant women in a rural district of the Far North Region of Cameroon". BMC Public Health 15 (2015): 454.

39. El Sheikh RM., et al. "Hepatitis B virus and hepatitis $\mathrm{C}$ virus in pregnant Sudanese women”. Virology Journal 4 (2007): 104.

40. Michault A., et al. "Prevalence of hepatitis A, B, C virus markers in Reunion Island (South hospital and Saint Pierre prison)". Bull Soc Pathol Exot 93.1 (2000): 34-40.

41. Ilboudo D., et al. "Mother-to-child transmission of hepatitis B virus in Ouagadougou, Burkina Faso". Med Trop 62 (2002): 99-100.

42. Sangaré L., et al. "Antenatal transmission of the hepatitis B virus in an area of moderate HIV prevalence, Ouagadougou, Burkina Faso". Bull Soc Pathol Exot 102.4 (2009): 226-229.

\section{Assets from publication with us}

- Prompt Acknowledgement after receiving the article

- Thorough Double blinded peer review

- Rapid Publication

- Issue of Publication Certificate

- High visibility of your Published work

Website: www.actascientific.com/

Submit Article: www.actascientific.com/submission.php

Email us: editor@actascientific.com

Contact us: +919182824667 